\title{
Vision in Context: The Situating of an ESL/EFL Curriculum
}

Virginia Sauvé

\begin{abstract}
Language enables us to make meaning together, and at the same time, limits those meanings we can attempt to communicate to each other. ESL/EFL programs must have as their central intent the enabling of people to make meaning in English. Such programs occur within a context of culture, time, and a sociopolitical web of circumstance, and within notions as to the meaning of education, of language and of culture. This overall context grounds the curriculum. Yet, as educators, we are also called with the learner to envision a better real-
\end{abstract}

ity. What occurs in our classrooms does so within the tension between context and vision. Our decisions, or lack thereof, determine whether our curriculum is to reinforce injustices inherent in the status quo or to enable people to create more just, more joyful ways of being together within this country and within our world. This paper explores some of the dimensions of context and vision and the tensions which may exist between them; it endeavours to point the way to curriculum as human praxis.

The writing of this paper is, in itself, born of Father Context and Mother Vision and, as such, has been a struggle of resolving seemingly opposing pulls. Do I compose from the heart or the head? Do I speak of experiences or concepts? Do I convey my thoughts in anecdotes or abstractions? Yet these are not really in opposition at all. For the vision which beckons me as an educator comes as a gift, a gift which calls from tantalizing nearness as I stand upon a rich and generous background of experiences with numerous persons struggling to gain their voice in our society through language learning and literacy.

I try to choose my words carefully knowing they will call forth different images for you than for me yet still needing to remain true to those they call forth for myself. I will not speak to you of target populations for this does violence to the soul of those so targeted. I want not even to speak of "people" per se, for too often in saying "people" we tend to lose sight of the individual persons within that categorization.

The art of academic rhetoric has never been mine. Yet I trust that the voice of experience carries with it a ring of truth which may resonate with your own experience as educators. If this can happen, then I hope that when I speak of vision, your own will stand before you as mine does for me. 


\section{A PERSONAL CONTEXT}

So that you might have some idea of the perspective for my vision, I will begin with a series of short, not immediately connected, anecdotes which I trust will begin to explain the passionate aversion I feel for a purely technical way of teaching divorced from the context of life around it.

\section{Little Boy Blue}

The first I call Little Boy Blue, for what else can I call a small Vietnamese-Chinese boy who appears at the classroom door one day, tears on his face, beside his nervous-looking father. "May I help you?" I ask the two strangers. "My son have bad toothache," the man replies. "Oh, I'm sorry," I say, wondering why he is at my door. "You must want the nurse's office down the hall," again wondering why someone would bring a child to an adult vocational centre for care. He remains at my door. I look puzzled. He looks frustrated. A voice behind me says, "Teacher, this my son, my husband." "Ah, come in," I say, knowing that the situation is no longer one that I can pass on or ignore. Suddenly, the problem is not his but ours. The lesson plan is now quite irrelevant in comparison with the activities which unfold that morning. I learn a lot about the problems immigrants face in getting adequate dental care. All the students learn that perseverance and information do yield positive results. And best of all, we know that Little Boy Blue will soon be Little Boy Sunshine. Now I understand why Chu's eyes have been half closed for the past two or three days-she has not slept for her son's crying.

Lest the reader assume that this was only a lesson in how to get dental care, I must assure you that information alone is not enough for those who lack the language and confidence to use it. The next day, a teenage girl appeared at the door with her father. I was not surprised when another mother's voice made a similar announcement behind me. I suddenly had visions of fifty family members coming to my door for help, but it was only two, and the whole class helped with responding to them. When a sense of community exists for a group of people, the problems of one are the problems of all. The text of one life is of interest to all. And the resources we share are inevitably greater than those of any one person in that community.

\section{The Mad Man}

That story reminds me of a second story which I shall call "The Mad Man." When I first came to the Alberta Vocational Centre about nine years ago, there was a man in our class who always sat glaring at me, 
his arms folded across his chest, his lips sealed as though vowed to perpetual silence. Occasionally, sounds escaped between them, but were so muffled as to be unintelligible. I tried everything I could think of to bring a smile to his face, assumed I must be the world's worst teacher, at least in his eyes, and resolved to ask him why he was so unhappy in the class. When I did, his furrowed brow shot high in surprise and he said, "Unhappy? No, very happy. Why say you I unhappy?" "Because you are always scowling at me." I mimicked his gesture. He laughed and then grabbed his face in obvious pain. He explained half in Spanish, half in English that he had had a very bad toothache for three weeks. The dentist had said that he needed a root canal, but the federal program sponsoring him was unwilling to pay for it and he had no money. They would pay to have the tooth extracted but he did not want that. To make a long story short, after checking out his story and discussing similar situations in class, I was able to get the money for his operation from my church. He was happy, but puzzled by this because he'd already decided that Canada was not a good place to live and was now forced to re-evaluate his judgment of Canadian people. If my commitment to him had stopped at language training, his learning would have been little. But my commitment was to him as a person. I still hear from this man on occasion. He's made a good life for himself in Canada.

\section{Expectations}

My third story concerns a beautiful young Vietnamese woman I shall call Muoi whom I met through her sister, who is my friend, and again soon after when she appeared as a student in our ESL class. In Vietnam she had been studying law. She is intelligent, highly motivated to learn, and not at all shy about saying things as she sees them. She was an excellent student whose English learning was swift in the all-too-short twenty weeks she had at the language school. About ten weeks after the class had finished, I was touring a garment factory in which I was about to do an English in the Workplace (EWP) class. Some of the workers ignored my presence and the rapid rhythm of their work continued its pace. Others managed a quick smile or a look of curiosity. Suddenly my name was shouted from across the floor and I looked over to see Muoi. Never shall I forget the images her face made me recall. She was obviously delighted to see me, yet there was also embarrassment and great sadness written across this once proud, lonely, face. She looked exhausted, miserable, defeated, overjoyed, and humiliated all at the same time. From law school to sewing collars on shirts in a place where there is no time to talk to anyone because time is money, in a place where most of the workers have skin rashes from the sizing in the fabric, and where the lighting turns everything into a 
surrealistic painting with oneself in the foreground. For what vision of life in Canada had her twenty weeks of ESL prepared her? Certainly not for this.

\section{A Slide Show}

The fourth story is about dignity and concerns my experiences at a large hotel, also the site of an EWP class. The images flash before me like slides in a slide show. Image One: the first day, as students filed into the room: four Filipino dishwashers and housemen, bowing respectfully; several maids coy and curious; a tall, proud French chef; an excited Chinese woman; a cook's helper; and an old Korean man in a blue coverall. Image Two: our first venture outside the classroom where I headed off to the elevator and they refused to follow because I had pushed the button for the guest elevator. While they were still explaining to me that they could not use that elevator, it arrived and two men looked at us expectantly from within. We got on, an uncomfortable group, and one of the two men in the elevator said to me, "You must be a teacher." Was it so obvious? Why?

Image Three: four older Filipino men leaping to their feet, bowing whenever I would ask them a question. When seated, they sat guardedly, heads bowed as if waiting for a reprimand. Image Four: the same four men a week later stretched out at their desks, laughing, suddenly looking much taller than I had realized they were. Progress, they were relaxing. Image Five: our last class. They were so happy, these men and women. Nancy had mustered enough courage to ask for a promotion after twelve years. She got it. The maids were now willing to tell the supervisor when they didn't understand her directions, and the old Korean man had received some overtime we discovered he had not been receiving. I was very satisfied that this had been a worthwhile educational project.

Image Six: the old Korean man, his eyes shining, silently puts an envelope into my hands. I open it to see a beautiful thank-you card, and-oh, no! - a crisp new fifty dollar bill. I am horrified and smilingly offer it back to him saying, "Oh Pak, thank you very much but I cannot accept this. I work for the government." Absolute pain mingles with mild horror at his comprehension of my words and his look freezes my hand in mid-air. He says slowly and carefully, "Please teacher, my face." His hand slowly touches his cheek as he looks beseechingly into my eyes and I am paralyzed with the enormity of my own comprehension. I return the money to the card and thank him. He begins to breathe again and his face relaxes into a grateful smile.

Image Seven: six months later, I am in the hotel for a union convention. I see a red uniform in which there is a person who looks familiar. $\mathrm{He}$ is vacuuming at the end of the corridor, and I make my way through 
the noisy conventioners to see if it is who I think it is. Yes, but what is wrong? The man is shorter again, hunched over his vacuum cleaner, head bowed as if to shut out the world around him. I come up and speak to him. His English has deteriorated. A brief smile flashes across his face as if images have come to his own memory. It quickly fades and the twinkle which came momentarily into his eyes is gone. I smile and leave, shaken with the knowledge that for him, our four months of working together was no more than a pleasant interlude in an otherwise bleak and lonely existence.

\section{Gifts}

My last story concerns a young Korean student with whom I worked last summer. She was one of twenty English teachers from Korea who came to Alberta to study curriculum in teaching English as a foreign language. Her English was better than most, but she was so shy that we seldom heard her speak in class. Her learning happened to no small degree through the medium of her journal which she wrote faithfully and at some length every evening. There were only four women in the group of twenty teachers, and all of them found it somewhat difficult to work out what it meant to be a woman in a Canadian classroom. My expectations of them were obviously quite different from those of a Korean teacher. Their custom, one which was rigorously demonstrated in the classroom, had been not to contradict what a man said. This was in direct opposition to the spirit of open discussion which I was promoting in class. Thus, this young woman's journal was filled with feelings, doubts, questions, and insights. She seemed very shaken with her culture shock. It was thus with great delight that I read the opening words of her final journal entry. She had written, "I came to Canada to learn more English, but I return home with Myself and Education."

These stories and hundreds like them form the backdrop against which the scenarios of this paper write themselves. The immigrant and foreign but not-so-foreign learners have touched my life deeply. The reality of their everyday lives calls out to me as a challenge and the myth of language training as the solution to their problems is dissipated before my eyes. I am called to redefine the context in which I do my work and, in doing so, have no choice but to redefine the nature of the work itself. As injustice emerges as a primary theme in my ESL experience, I am called also to envisage what might be possible in a world where immigrants were valued for their differences as well as for their labour, and where our social fabric might be enriched by diversity rather than torn apart by it.

I also envisage a world where people of all countries have access to the resources necessary to lead happy lives together. What does that mean for those who would teach English in the so-called developing 
countries? I am profoundly disturbed at what appears to be happening when North Americans go to other countries to teach English. There is a hidden agenda that "our" way is better than "their" way, that our technology is the answer to the woes of the world, and that English speakers will lead the way to salvation. The context of North American EFL, whether here for visitors or in another country, is absolutely different from that of ESL. What understandings of curriculum are necessary to situate our teaching in the appropriate context? We have many questions to ask ourselves.

\section{CONTEXTS FOR EDUCATION}

Everything a person is, everything a person does, is situated within a context of language, of culture, of history, politics, economics, time, and place. If we want to work towards a better society for ourselves and others around us, we need to search for an intimate understanding of our context, of that which both shapes and transforms the present.

\section{Language}

Let us begin with language. We who speak English are largely unaware of the ways in which our language itself structures our lives. It is in the nature of language that one is aware of it only when it is not working as usual. We think that our English forms reflect the real world and, indeed, for us they do, but not for everyone.

$I$ have begun the arduous process of learning a minimal amount of Korean and am constantly frustrated by the complexity, for me, of this language system. I asked my teacher, "How do you say 'food' in Korean?" His response was, "Well, it depends who is going to eat it." When working with a young Chipewyan Indian years ago, I wanted to hear what his language sounded like and asked him to say, "The dog jumped over the fence." He looked puzzled and said, "Well, I can't just say that." "Why not?" I asked. "Because I don't know if the dog was male or female, what kind of fence it was and if there was water on the other side or not." How small and narrow is the world of the English language for those whose languages define certain aspects of their reality in finer detail. How very traumatic and confusing it must be for some of our students to realize that their world does not really translate into English and our world is likewise a mystery to them. I remember my efforts to work with one particular young Chinese-speaking woman who had had no formal education in her country. If I said "chair" and put my hand on a chair, she would smile and say "chair" knowingly. She understood. But as soon as I said, "This is a chair," her eyes would seem to glaze over and she would wait silently, no 
longer able to acknowledge even that "chair" was "chair." As I thought about it, I realized that indeed the words 'this,' 'is,' and 'a' relate to concepts which, for one who may not express them in the other language, may be mystifying indeed.

\section{Culture}

Language is closely related to culture. Culture is so complex that I hesitate to even open the door of exploration into culture as context. I do, however, think it is important to question the popular understanding of Canada as a multicultural country. What does that mean? I frequently hear complaints about immigrants taking jobs away from Canadians. Little does it matter to these complainers that many of these "immigrants" are Canadians. A Canadian, as implied by some, seems to be someone with a white face who was born here. I think, as Canadians, we have the opportunity to explore what it means to become a multicultural society. It seems to me that this will not happen until it is acceptable not only to eat and dance like a Pakistani but also to think like one. Canadians expect that newcomers, when in Rome, "do as the Romans do." In many other cultures, the rule is that people are to do all they can to put the stranger at ease, to enable that one to feel at home. It is confusing for the stranger or newcomer to Canada to be expected to be something other than what she or he is.

The context of culture within which we work is, like language, a context of between-ness. What does it mean to teach others who exist in that zone of between? What does it mean to teach teachers to teach in this context? I believe it means that we must be less technical and more critically reflective of what we do and are, that we must set aside our "how?" questions for a time and begin to ask and re-ask "what?" and "why?" It means we must negotiate with those from different cultural contexts to arrive at an understanding of what it means to share a common country which purports to be multicultural.

\section{Settlement}

In Canada, the task of the ESL teacher working with immigrants lies much more, I believe, in settlement than in language training. Granted, learning the language is an important part of settlement but it is hardly all of it, nor do most ESL teachers behave as if it were. There is a lot of information-sharing in an ESL curriculum. We teach units on housing, banking, and social graces. Beneath such teaching, however, there is an ideology. For those who deny this, I am reasonably certain of what their ideology is, namely that of maintaining the status quo. Those who have this ideology see their job as that of helping people toifit into the world as it is. Such teaching does not question how the world is, 
nor does it have much sympathy for the learner who protests about that world. However, there is a growing number of educators in Canada who are beginning to address the larger issue of transforming that world. I know that sounds lofty and impossible but, historically, this perspective on the part of any individual who has pondered intentional change has always sounded that way. Fortunately for us, the apparent impossibility has not prevented such people from engaging themselves and others in the vision they had.

Generally speaking, in Canada the assumption is that immigrants will start at the bottom of the ladder and the most "capable" will work their way up. In other words, when immigrants speak like us, dress like us, act like us, and work like us, they have achieved success. Such success is real only in terms of a system which is dependent on win-lose, richpoor, boss-labourer, giver-taker polarities. An alternative ideology to an educational system designed to help people to take their appropriate station in the current structure of this country is one designed to enable people to have more power over their own lives on an individual and collective basis. A curriculum which does this is not one in which the teacher decides what the class is to learn, how they will learn it and how they will be evaluated on that learning. An empowering curriculum is one which emerges from the being of the participants-teacher and learner-within it. It is based not on specific objectives, but rather on guiding principles. Such a curriculum views settlement not as assimilation but as a re-naming, re-shaping, and re-making of one's life in a new context. By enabling learners to see their choices and responsibilities within the classroom, this curriculum helps learners recognize that they have choices, and also the power and the ability to make them. The hidden agenda of the technical, prescribed curriculum is that there is only one way and that is the teacher's way.

\section{Education}

A primary context within which we work is the very notion of education. The word is familiar to all, yet we have different understandings as to what it means. For most, education is what happens at school. It means the teaching of something that the student did not know but the teacher does, be it language, math, literacy or "facts." I do not call that education but training.

It is helpful to distinguish between education and training as modes of coming to know. Education is from the Latin root <educere> to lead forth. Training is from the root <trahere to pull or drag. There is a big difference between the teacher who beckons and the teacher who charges forth with someone in tow. The one who beckons is also willing to be beckoned to. The one who pulls has no questions as to the direction of the activity. The teacher who beckons sees curriculum as a 
fluid, dynamic, emergent phenomenon. The teacher who pulls sees curriculum as the road map.

I made an observation three years ago concerning language learning. A young woman with literacy problems, personal problems, and great shyness was with me for twenty weeks after which she was not able to find work and had no money to continue her studies. I asked her if she would like to work as a volunteer bilingual aide in the class until she could find work or continue her studies. I said I would not have much time to spend with her but would continue to respond to her daily journal and guide her to readings and self-study materials as together we identified her needs and interests. She was delighted and stayed with me for another five months.

In the long run, the interesting point was this: she was tested at the beginning of her formal studies, midway point, and at the end. She had made steady gains throughout. For my own interest and hers, I then invited her to continue participating in the tests every ten weeks while she was a volunteer. Her test scores continued to climb at the same rate even though she was working in the same level of class she had been in as a student, and received very little extra guidance from me. Her English had definitely improved. I needed her help-she rose to the occasion. She did photocopying and other office work in addition to her bilingual services and thus had to communicate with a variety of different people. She could not get fired for her mistakes because she had never been hired, and everyone was very supportive of her efforts and grateful for her help. What this indicates to me is that language is learned through meaningful experiences within it, more so than through looking at it.

I like to begin with the assumption that the learner and I have a lot to say to one another. The responsibility for doing that belongs to us both. We can choose to attend to language only when it becomes a priority. I hold the learner accountable for her or his own learning, and I hold myself accountable for ensuring that I provide the tools and the atmosphere in which she or he can do that. Who am I to say that the learner will learn better if I select the topics from day to day or engineer the learning of grammar in a neat sequential fashion? Do I not know that the adult is capable of determining what language is relevant, interesting and meaningful to her or him? Do I not hold that the adult is capable of acquiring the language she needs to express herself and her world, to make sense of her life and to act meaningfully within it? I do hold that the adult is capable of these, which is not to say that my classes are nothing but endless chatting. They are not. They are purposeful, but our purpose is worked out between us as I beckon, challenge and question, and the learners respond to me or I to them. Our dialogue in English is meaningful because it is ours, not mine alone. 


\section{VISION FOR EDUCATION}

If this vision of an ESL class seems very different from the highly structured, technical classes most of us are used to seeing, why is that so? The words of a "Draft National Declaration on Adult Education," which I received recently from the Canadian Association for Adult Education, suggest that the mandate of the adult educator should be quite different from that reflected in the average adult ESL classroom. The draft is, we are told, very similar to one which they put out in 1943, a fact which is amazing in light of its contents. We read, "Fifty years ago, the Canadian Association for Adult Education declared that the adult education movement is based on the belief that quite ordinary men and women have, within themselves and their communities, the spiritual and intellectual resources adequate to the solution of their own problems," and later, "Canada can become a society where full social participation by women, native peoples, new Canadians, the disabled, the poor, the unemployed, is guaranteed. Adult education has become a worldwide movement for personal and social transformation."

If this is the vision of adult education and we are working with adults, why is this not our vision? For that matter, is it only adults this applies to? How do we expect children to suddenly become responsible adults when all their decisions are made and watched over for them through twelve years of school?

It is my belief that the form of education suggested by the draft declaration is not typical of the average ESL or EFL class, because historically we have seen these areas of work primarily as a branch of applied linguistics. ESL research is largely restricted to empirical, quantitative studies which reduce the language and the learning experience into minutiae to be held under the microscope for our analysis. Such an approach to research seems not to help us to understand either the wholeness of personhood nor the complexities of a society woven of many cultures and histories. Such research assumes language is only a tool of communication and asks nothing more than how we can better construct teaching programs which focus on that tool. A tool can be picked up or set aside. I can no more set my language aside than I can my head. It is me. It structures who I am and the fabric of my life.

As a language learner, I am also a learner of life. As I am taught by another, I learn not only language but also who I am in the eyes of others, what is all right to do and not to do. When I am lectured at and ordered about, I feel like an object, not a person. I do not want to speak in such a class because that teacher is not interested in what I say, but only how I say it.

In a 1983 article, Jack Richards cites the following Chinese proverb:

Not to let a word get in the way of its sentence 
Nor to let a sentence get in the way of its intention

But to send your mind out to meet the intention as a guest.

THAT is understanding ${ }^{1}$. (1983, p. 80)

Is this not what fluency is about? Such fluency is found in dialogue, not in worksheets.

The vision I hold for education is one in which people are not segregated by social distinctions in their learning enterprises, but are finding their common humanity together. In a conversation with Walter Altree, Walter Ong said:

The assumption that we are so privileged that everyone wants to be like us is a peculiarly American problem. We can get over it a little bit if we undergo the humiliation of trying to learn another language. If we are full human beings, we are called on to let ourselves be absorbed into other people's points of view as well as to welcome others into the country. (Altree, 1973, p. 31)

Ong went on to say:

... if you are going to provide a liberal education, you also have to liberate the person from his own world so that he achieves some distance from it, knows other options. This makes it possible for him to understand his own position. To understand anything we need both closeness to it and distance from it. (p. 33)

We call ourselves educators and education means new understandings, new skills, new knowledge. Ong calls upon us to reflect and question, but is it possible to do that independently of acting upon one's insights? I see no justifiable reason for making language the end of instruction when language can be acquired as well or better by letting it be the medium of education rather than its end and sole purpose. We cannot genuinely advocate communicative competence without advocating the communication of meaning. Thus, the real question we have to ask ourselves as educators is, "In what ways can we facilitate meaningful experience for the learner and opportunities to communicate that in English?"

\section{PRINCIPLES FOR A CURRICULUM}

This question causes me to reject an explicit curriculum of predetermined objectives, whether they be linguistic or thematic in content, in favour of a curriculum which is seen as an attitude of meaningful inquiry. The structure of my curriculum is, therefore, a set of principles which I would like to share with you.

\section{Participation}

The first of these principles is participation. By that I do not mean 
only active as opposed to passive learning, although that is part of it. By participation I mean participation in decision-making, in the determination not only of content but also of process. As a teacher, my role shifts from that of director to that of facilitator. I, too, am a participant. I have some knowledge the learners do not have. They have knowledge I do not have. English is the means by which we have agreed, generally, to share our knowledge and act out of it.

\section{Community}

The second is community. In the very traditional classroom, the key relationship is between the teacher and the learner with both intent on getting from point $\mathrm{A}$ to point $\mathrm{B}$ by the shortest, most efficient route. Such a goal assumes that the teacher and student agree on what points $\mathrm{A}$ and $\mathrm{B}$ are. If that assumption is accurate, the student learns and both teacher and student are happy. If the assumption is not accurate, the two are working at cross-purposes to the frustration of both. Furthermore, there is no need for any one student to relate to any other since the presence of the other is largely irrelevant to the task. Such a view results in many casualties in the educational system and an alienation among human beings.

I work hard to establish community in my classes. I know it is there when Dung's story is of interest to Kitty, when Muoi's problem is taken on by Reinaldo as his problem too. I know it is there when the learners continue their work cooperatively whether I am in the classroom or temporarily out of it. I know it has been there when, long after a course has finished, people continue to get together to share their lives and to enjoy one another's company. Without community, there may be little acceptance between different cultural groups. With intolerance there is not the climate for self-esteem which is so essential to language learning. It is not enough to say, "Yes, it's nice when there is community in a class." It does not necessarily happen by itself. It takes work, the teacher's work and the learners'. In a community of people, there is trust. It is all right to make mistakes, to admit to fear and anger. Without such trust, curriculum will not emerge and the teacher will be almost obliged to perform a traditional prescriptive role.

\section{Commitment}

Commitment is a third principle in a human curriculum. We have individual limitations and other commitments, but how is it determined that my commitment to another human being ends at 4 p.m., or on Friday, or at the end of a course? Either we are real people who act in relation to others on the basis of real limitations, or we are role players who do our jobs and then go home to our "other" world. We want our 
students to be committed to their learning. The best way to ensure that seems to be by our genuine commitment to their personhood and to our own.

If you remember back to your experience of public school, who were the teachers who really made a difference in your lives? For me, there was a French teacher who had a few of us to tea at her home and talked of her experiences at the Sorbonne. (I majored in French during my first two years of university.) There was one Sunday School teacher who visited me in the hospital and another who took a group of us teens camping. (I remember them; I don't remember the others.) My lessons were not in what they said but in how I experienced myself and others in their presence. Their commitment to me enabled me to develop my own sense of commitment in life.

\section{Accountability}

A fourth principle is accountability. I hold learners accountable for their own learning. One means by which I do that is by not anticipating and thus precipitating each learner's precise needs and questions. I could, as you could, but I try not to because I think it is more important that learners articulate their own needs and thus deserve the credit for succeeding in meeting those needs. For example, when someone looks puzzled, I know they have not understood, but I wait hoping to hear and to actively help, if necessary, the person to say, "I don't understand." I know too many people who have lost jobs because they were afraid to tell the employer they did not understand and thus performed the wrong task. When students are working on photostories, I try hard not to tell them the story as I see it in the pictures but to get them to ask for the language they need to tell their own stories which are frequently totally different from my interpretation of what has happened. In this way, not only is their story produced rather than someone else's but they have a means and a habit of going out into the wider world outside the classroom and getting what they need and want to know in the language.

\section{Praxis}

A fifth principle is praxis. Praxis, as I understand it, is a dialectical process of reflection and action. It involves questioning, a deep critical questioning aimed at coming to fuller, more meaningful understandings of our lived experience of the world. Such reflection places a high value upon our lived experience for it is there that the contradictions lie, the hidden assumptions, the unseen ideology which governs and, to the extent that it is unseen, limits our freedom as human beings. Praxis is a social activity, for we live in a shared world. Out of genuine dialogue, 
we come to understand not only the Other but also our Self, and in such understanding lies the possibility of choice.

To choose is to act. Reflection would be empty indeed if it did not lead us individually and collectively to act differently within our world. Some people say to me, "Come on, Virginia, it is not the job of teachers to change the world but to help learners to cope better within it." I say it is both, for if it is not the educator, among others, who is to enable transformation, then to whom, I ask, may we assign the task? Poverty for vast numbers of people, fear of nuclear annihilation, massive pollution of nature's gifts to all creatures, misery in the lives of many-these realities call out for every person to respond, to take responsibility, to understand, to act on that understanding. "But we are language teachers ... ., you say? Yes, and language is the medium in which we share our realities, understand them and act within them. To speak to one another across cultures, we need language, not only in the workplace and the marketplace, not only as a functional, practical necessity but as a medium in which to make sense of our lives together and to live out our freedom to act as subjects in our world. To act reflectively, to reflect actively, this is our praxis.

\section{CONCEPT OF CURRICULUM}

I have spoken of context and of vision. I have shared some of the principles which guide my teaching/learning. What I have yet to do is share what I understand by the term curriculum. To say that curriculum is only the plan by which the teacher approaches her or his teaching is somehow to lose sight of the importance of the participant's experience of the learning situation. In school, in play, we have learned too often that to win means that someone else has to lose. That is the nature of the games we play. Competition is high on the agenda in schooling. Yet on how many curricula does it appear as a goal? We know we need to move towards cooperative modes of relating to one another but we do not know how to approach the task because we do not recognize how strong the curriculum of competition and individualism has been in our own social experience.

I speak of curriculum in two ways. For me, it is curriculum-as-plan and curriculum-as-lived-experience. Curriculum-as-plan refers to the guiding principles, the general intents, displays and activities, and the on-going evaluation which are potentially available for a group of people who choose to enter into them. I believe in a negotiated curriculum but I prefer to call it an emergent curriculum. Negotiation belongs to the world of business and commodity. Emergence belongs to the world of living and discovering. 
Curriculum-as-lived-experience is a reflective process, a process of discovering and evaluating where it is we have been and where it is we wish to go. It is no less a valid documentation of the educational enterprise than the prescriptive documents to which we are accustomed and is, in fact, a much more meaningful account of the learning experience. It is participatory in that a whole picture is one to which all participants have offered their gifts.

\section{REFERENCES}

Altree, W. (1973). Why talk? San Francisco: Chandler and Sharp.

Richards, J. (1983). Listening comprehension: Approach, design, procedure. TESOL Quarterly, 17(2).

\section{THE AUTHOR}

Virginia Sauvé is entering her third year of a Ph.D. program in curriculum for adult ESL learners at the University of Alberta. She has over twelve years of teaching experience including English in the Workplace and ESL literacy. For the past two summers she has taught a curriculum course to EFL teachers from S. Korea. In addition, she has been working with low-income women in a participatory education project and is writing a book for Grant MacEwan Community College entitled "From One Educator to Another: A Window on Participatory Education." Virginia is the outgoing Past-President of ATESL (Alberta). 